\title{
Preliminary results of cervical impedance measurements
}

\author{
Thiago Kira de Souza Saito ${ }^{1}$, Rafael Augusto Pedriali ${ }^{2}$, Cinthia Mara Gabella ${ }^{3}$, Maurício Chaves Junior ${ }^{3}$, \\ Elvio João Leonardo ${ }^{1 *}$ \\ ${ }^{I}$ Department of Informatics, State University of Maringa, Maringa, PR, Brazil. \\ ${ }^{2}$ Department of Chemical Engineering, State University of Maringa, Maringa, PR, Brazil. \\ ${ }^{3}$ Department of Medicine, State University of Maringa, Maringa, PR, Brazil.
}

\begin{abstract}
Introduction: In this work, we report the development and initial tests of a measuring system that is used to measure the cervical electrical impedance with the purpose of assessing cervical ripening. The objective is to offer a system that provides real-time information about the cervical electrical impedance and, indirectly, of the cervical ripening with the aim of preventing premature birth. Methods: Probes were developed and initial tests were performed. The probes used had electrodes that are far apart, with the assumption that in such cases deeper layers of the cervical tissue are measured. Results: Preliminary measurements were performed in a single session on a non-gravid uterus, using as excitation signal a sinusoidal wave with frequency varying from $3 \mathrm{kHz}$ to $100 \mathrm{kHz}$. Results indicate, as expected, that the magnitude of the impedance is inversely proportional to the frequency, indicating capacitive impedance. Conclusion: Preliminary results were very encouraging. However, further measurements must be performed to correlate the impedance to the cervical ripening.
\end{abstract}

Keywords Human uterine cervix, Cervical ripening, Electrical impedance measurement, Electrical impedance probe.

\section{Introduction}

Pregnancy is considered high-risk if it endangers the life of the mother or the baby. Ideally, this type of pregnancy should receive continuous monitoring to detect and prevent complications, particularly those that may lead to premature labor. However, continuous monitoring requires the intensive use of equipment and personnel, which usually is not possible in the public health system, or even difficult to get in the supplementary health system. As a result, in many cases the detection of complications is not performed early enough to allow proper treatment and the pregnancy ends in premature birth, at great risk to both mother and baby.

Premature birth, i.e., a birth occurring with less than 37 weeks of gestation, is considered one of the major causes of infant death and it is the source for a number of sequelae that affect the survivors (Blencowe et al.,

This is an Open Access article distributed under the terms of the Creative Commons Attribution License, which permits unrestricted use, distribution, and reproduction in any medium, provided the original work is properly cited.

How to cite this article: Saito TKS, Pedriali RA, Gabella CM, Chaves Junior M, Leonardo EJ. Preliminary results of cervical impedance measurements. Res Biomed Eng. 2018; 34(2):110-114. DOI: $10.1590 / 2446-4740.05617$.

*Corresponding author: Department of Informatics, State University of Maringa, Av. Colombo, 5790, CEP 87020-900, Maringá, PR, Brazil. E-mail: ejleonardo@uem.br

Received: 25 September 2017 / Accepted: 12 April 2018
2013). Critical to the outcome of a pregnancy, the uterine cervix is located at the lower end of the uterus and serves two major functions: before term, it must remain closed to allow the fetus development, and at the end of pregnancy, it must dilate to allow delivery. At term, the cervical preparation includes softening, ripening, shortening, effacement, dilation, and finally birth. One way to predict the initiation of labor would be to quantify cervical ripening. A subjective assessment of the ripeness of the cervix, along with the fetal station, is a traditional method to predict if induction of labor is required or if a spontaneous preterm delivery is likely. For instance, the Bishop score (BS) grades patients by assessing the cervical consistency, effacement, position and dilatation, as well as the fetal station (Bishop, 1964). However, the usefulness of such assessment is not unanimous, as indicated, for example, in Hendrix et al. (1998) and Pandis et al. (2001), where BS is evaluated negatively with regards to its accuracy and repeatability.

The extracellular matrix $(\mathrm{ECM})$ is an extracellular connective tissue that has the load-bearing function of the uterine cervical tissue (Uldbjerg et al., 1983). It accounts for $85 \%$ to $90 \%$ of the cervical stroma, while smooth muscle constitutes the remaining (Danforth, 1947; Petersen et al., 1991). The ECM is mainly constituted of collagen and it is similar to other fibrous connective tissues (Kleissl et al., 1978). During most of the pregnancy, cervical collagen remains organized in fibers, resulting in a rigid cervix. That changes during cervical softening and ripening, as the collagen organization 
disassembles, together with the cervical tissue hydration (Cunningham et al., 2010). Currently, these cervical tissue microstructural changes can be inferred by using two techniques: light-induced fluorescence spectroscopy (LIF) and electrical impedance spectroscopy (EIS) (Etemadi et al., 2013). The former is based on the auto fluorescent properties of the collagen cross-links; and the latter is based on the electrical impedance characteristics of the cervical tissue.

The use of electrical impedance to assess cervical ripening has been reported in the literature, e.g., Avis et al. (1997), Etemadi et al. (2013), Gandhi et al. (2006a; 2006b), Hoe et al. (2004) and O'Connell et al. (2000). Avis et al. (1997) presented in-vitro measurements of the electrical impedance of cervical tissue from samples taken at caesarean sections, and reported differences between term and preterm samples. In O'Connell et al. (2000) the authors performed measurements of electrical impedance of pregnant and nonpregnant women, and indicated that the results might be as good as those obtained by BS. Hoe et al. (2004) proposed a bioimpedance probe that might be used to detect preterm labor. Laboratory in-vitro tests were conducted on various collagen concentrations with success. In Gandhi et al. (2006a) the authors observed that the impedance increases significantly only in the third trimester of gestation. The characteristics of the measuring probe (e.g., the distance between electrodes) are considered in Gandhi et al. (2006b). Jokhi et al. (2009) performed EIS measurements on women admitted for induction of labour, using a number of different probes, in conjunction with BS. In their case, only the larger probe $(12 \mathrm{~mm})$ was predictive of any labour. Combined results from LIF and EIS were used in (Etemadi et al., 2013) to assess microstructural changes in the cervix. Initial results were presented for a 6-electrode transvaginal probe. Considering the works listed above, and others reported in the open literature, a relationship between electrical impedance and cervical ripeness seems evident. This is probably intuitive, since expressive changes in the cervical stroma during pregnancy should reflect in changes in its electrical conductance. There is, however, significant influence on the results of the shape of the probes used, which has not been clearly exposed yet. Therefore, it seems that this research topic still deserves further investigation and, in fact, it still attracts considerably interest.

In this work, we report the development and initial tests of a measuring system that is used to measure the cervical electrical impedance with the purpose of assessing cervical ripening. The objective is to offer a system that provides real time information about the cervical electrical impedance and, indirectly, of the cervical ripening with the aim of preventing premature birth. We consider probes where electrodes are far apart, with the assumption that in such cases deeper layers of the cervical tissue are measured. Clearly, a system as the one envisioned here, that provides advanced information about the imminent preterm birth may have a major impact on the health of pregnant women and their babies.

\section{Method}

The system assembled to measure the cervical electrical impedance includes an impedance measurement circuit, responsible for generating the excitation signal and performing the measurements, cervical probes, which are positioned around the cervix, and a personal computer, responsible for controlling the system operation and for recording the data.

\section{Impedance measurement circuit}

The impedance measurement circuit is based on a high precision impedance converter integrated circuit (IC) AD5933 (Analog Devices, 2013), which combines a programmable frequency sine-wave oscillator and a 12-bit analog-to-digital converter (ADC). An off-the-shelf development board EVAL-AD5933EBZ (Analog Devices, 2007), which harbors an AD5933 IC and other circuitry, was used to generate the excitation sine-wave signal with up to $1.98 \mathrm{~V}$ peak-to-peak (Vpp) and frequency of up to $100 \mathrm{kHz}$. The AD5933 IC is a two-electrode impedance measurement circuit, with the measurement load ranging from $1 \mathrm{k} \Omega$ to $10 \mathrm{M} \Omega$ (Analog Devices, 2013). For small impedances, from $100 \Omega$ to $1 \mathrm{k} \Omega$, an external buffer is required due to the higher current flowing through the load, i.e., the unknown impedance (Analog Devices, 2013). In the development board EVAL-AD5933EBZ, an operational amplifier (OpAmp) is used for this purpose of boosting the output current of the AD5933 IC (Analog Devices, 2007). The frequency of the excitation sine-wave signal is defined using a 27-bit register, which allows for a frequency resolution smaller than $0.1 \mathrm{~Hz}$ (Analog Devices, 2013). The digitized magnitude and phase measurements were then transmitted via a USB (Universal Serial Bus) interface to a portable computer. This computer was responsible for the data acquisition, frequency and excitation voltage selections, and overall control of the development board.

\section{Cervical probes}

A number of cervical probes were used during trial tests. Each probe was constructed using a $5 \mathrm{~mm}$ in diameter dental silicone tube that was bent in a U-shape, and tied at the ends using dental elastic bands. The end result was a 20 to $25 \mathrm{~mm}$ in diameter ring flexible enough to adjust to the cervix. Stainless steel contacts were embedded in the silicone tube to act as electrodes. Each electrode was fastened to a stainless steel wire, and a $1 \mathrm{~mm}$ in diameter dental silicone tube was used to cover each wire lengthwise. The differences between probes are the number of electrodes and their positions around the ring. A pair of Cheron tweezers was used to place and 
remove the probe. All instruments and materials were sterilized before and after use.

Preliminary measurements were performed using two probes, identified as types $\mathrm{R}$ and $\mathrm{U}$, described in the next section. The measurements were authorized by the Permanent Ethical Committee for Research on Human Subjects of the State University of Maringa and performed in a single session on a non-gravid uterus, in vivo, using as excitation signal a sinusoidal wave with peak-to-peak voltage $V_{p p}$, with $V_{p p}=0.2 \mathrm{~V}$ and $V_{p p}=2 \mathrm{~V}$.

The complete measuring system is shown in Figure 1. It includes a portable computer connected to the development board EVAL-AD5933EBZ via a USB interface. On the other side, the board is connected to the measurement probe using stainless steel wires.

\section{Equivalent circuit}

It is known that the electrical impedance of biological tissues is inversely proportional to the frequency, mainly because the cell membrane functions as a capacitor. In addition, there are the resistances associated with the extra cellular and intra cellular fluids, resulting in the compound equivalent circuit depicted in Figure 2 (Fricke and Morse, 1925), (Schwan, 1957). In the current work, we use the circuit of Figure 2 to model the impedance measurements realized.

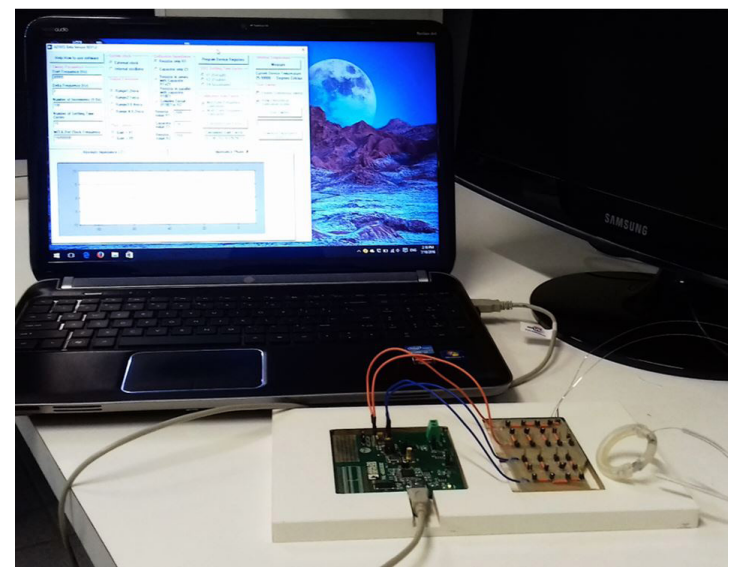

Figure 1. The complete measuring system.

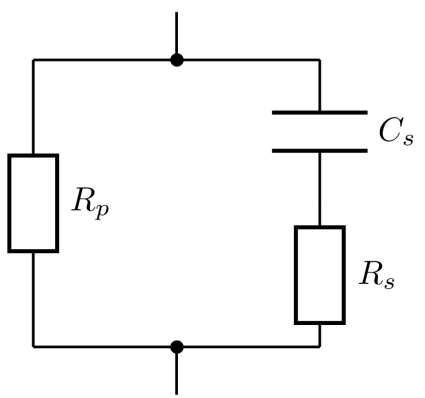

Figure 2. Biological tissues equivalent circuit (Fricke and Morse, 1925; Schwan, 1957)

\section{Results}

Preliminary measurements performed using probes $\mathrm{R}$ and $\mathrm{U}$ are presented in the following. Before each measurement session, the device was tested and calibrated using a known impedance value, in accordance with the recommendations of the development board's manufacturer (Analog Devices, 2007). Also, around four to five repeated measurements were performed in each session to confirm the results. However, since we have only preliminary results, no estimation on the measurement uncertainty was performed.

\section{Probe $R$}

Probe $\mathrm{R}$ is depicted in Figure 3, showing that it contains four separated electrodes. However, for the measurements reported here, the electrodes on each side of the probe were connected in parallel. Results for the impedance magnitude and phase are shown in Figures 4 and 5, respectively. In the figures, $V_{p p}$ is the peak-to-peak voltage of excitation signal. As expected, the magnitude of the impedance decreases with the increase of the frequency. Similarly expected, the phase of the impedance increases with the increase of the frequency. Considering a visual inspection of the figures, it can also be noted that a higher excitation voltage translates into smoother curves, and supposedly in more accurate measurements. Table 1 contains the parameters of the equivalent circuit of Figure 2 applied to the results of probe R. Based on the resemblance between the impedance curves (magnitude and phase) obtained from the measured data and from the equivalent circuit, it can be shown that the equivalent circuit offers a good fit for frequencies above $20 \mathrm{kHz}$.

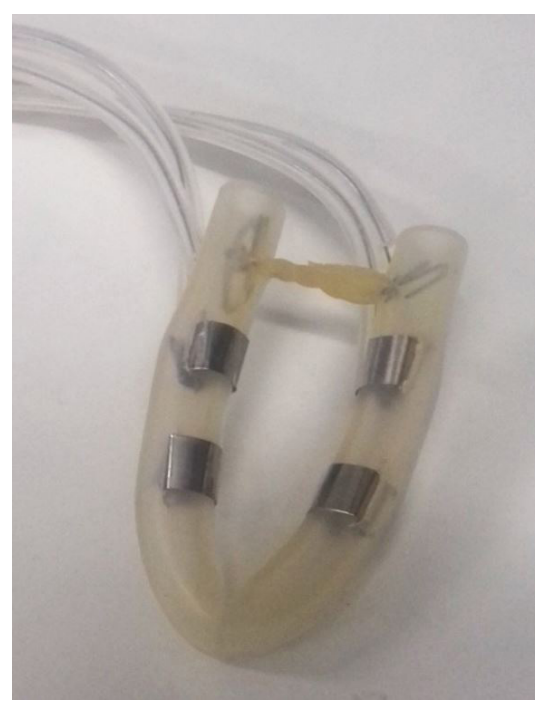

Figure 3. Probe R, with four electrodes. 


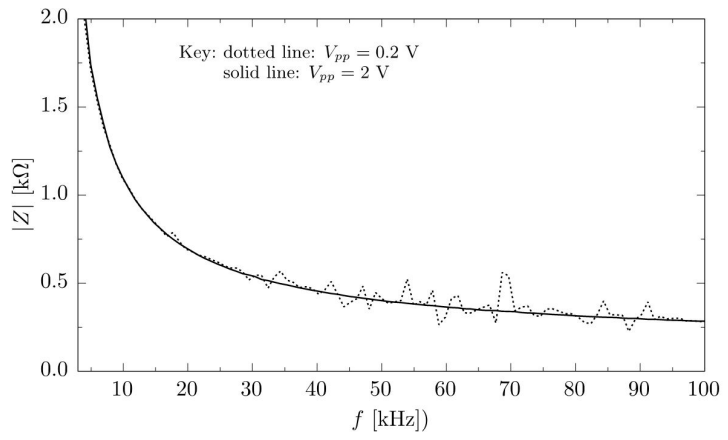

Figure 4. Impedance magnitude measurements for probe R. Vpp is the peak-to-peak voltage of the excitation signal.

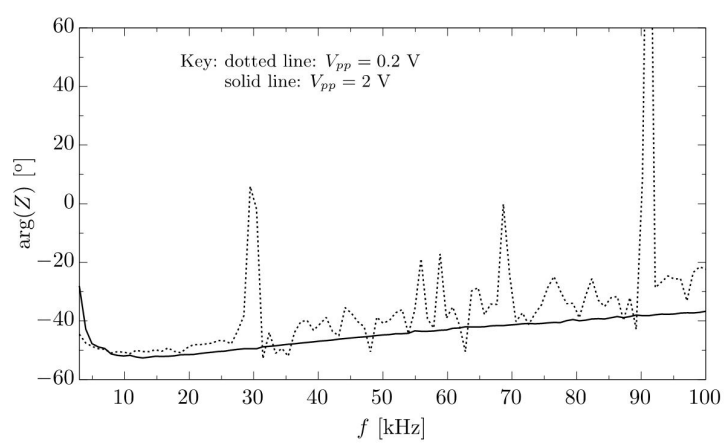

Figure 5. Impedance phase measurements for probe R. Vpp is the peak-to-peak voltage of the excitation signal.

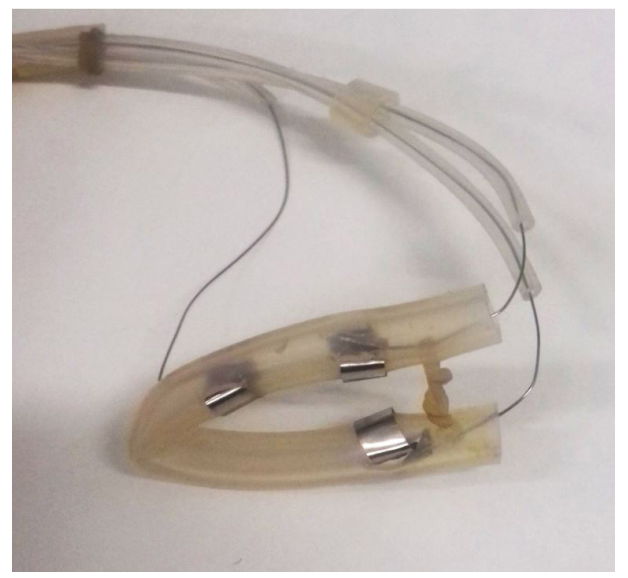

Figure 6. Probe U, with three electrodes.

\section{Probe $U$}

Probe $U$ is depicted in Figure 6, showing that it contains three separated electrodes. However, for the measurements reported here, only the two opposite electrodes used. Results for the impedance magnitude and phase are shown in Figures 7 and 8, respectively. As mentioned above, $V_{p p}$ is the peak-to-peak voltage of the excitation signal. In addition, as already observed, the magnitude and phase of the impedance

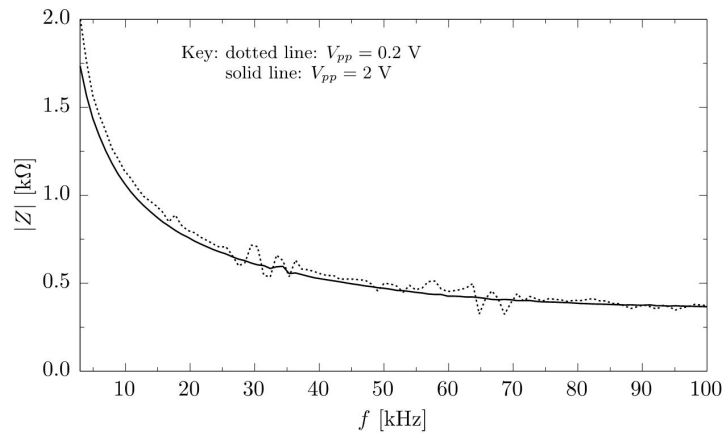

Figure 7. Impedance magnitude measurements for probe U. Vpp is the peak-to-peak voltage of the excitation signal.

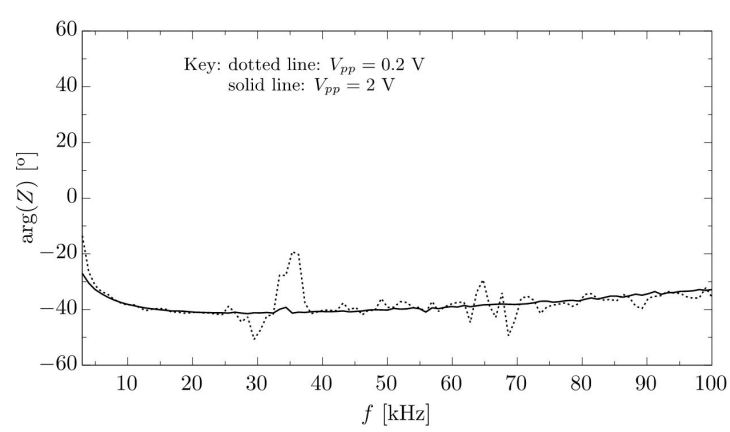

Figure 8. Impedance phase measurements for probe U. Vpp is the peak-to-peak voltage of the excitation signal.

Table 1. Parameters for the equivalent circuit.

\begin{tabular}{ccc}
\hline & Probe R & Probe U \\
\hline $\boldsymbol{R} \boldsymbol{p}$ & $1.2 \mathrm{k} \Omega$ & $1.1 \mathrm{k} \Omega$ \\
$\boldsymbol{R} \boldsymbol{s}$ & $250 \Omega$ & $300 \Omega$ \\
$\boldsymbol{C s}$ & $6.5 \mathrm{nF}$ & $5.3 \mathrm{nF}$ \\
\hline
\end{tabular}

respectively decreases and increases with the increase of the frequency. Table 1 contains the parameters of the equivalent circuit of Figure 2 applied to the results of probe $U$. Based on the resemblance between the impedance curves (magnitude and phase) obtained from the measured data and from the equivalent circuit, it can be shown that the equivalent circuit offers a good fit for frequencies above $20 \mathrm{kHz}$.

\section{Discussion}

In this work, we report the development and initial tests of a measuring system that is used to measure the cervical electrical impedance with the purpose of assessing cervical ripening. Results indicate, as expected, that the magnitude of the impedance is inversely proportional to the frequency, pointing to capacitive impedance. Further measurements must be performed to correlate the impedance to the cervical ripening. 
When the results of the two probes used in this work are compared, it can be seen that the four-electrode probe offer a slightly larger capacitance, probably due to the extra electrode and the intrinsically larger capacitance it produces. On another side, the excitation voltage influences the steadiness of the measures. The larger the voltage, the lower the ripples in the resulting impedance curve as a function of the frequency.

Previous works published in the literature (Avis et al., 1997; Etemadi et al., 2013; Gandhi et al. 2006a; 2006b; Hoe et al., 2004; O'Connell et al., 2000) produced results in line with those reported here. However, none of them include an equivalent circuit for the cervical tissue, as it is done here. The equivalent circuit is important because it seeks to model the cervical tissue using objective parameters, and therefore facilitates the modeling. Even though, it is important to state that the equivalent circuit of Figure 2 is not a novel contribution of the present work.

\section{References}

Analog Devices. Evaluation Board for the 1 MSPS 12-Bit Impedance Converter Network Analyzer, EVAL-AD5933EB Preliminary Technical Data. Norwood: Analog Devices; 2007. 32 p.

Analog Devices. 1 MSPS, 12-Bit Impedance Converter, Network Analyzer, AD5933 - Datasheet. Norwood: Analog Devices; 2013. 40 p.

Avis NJ, Lindow SW, Kleinermann F. A preliminary investigation of electrical impedance measurements of the cervix as a method of monitoring and predicting the onset of labour. In Proceedings of the 18th Annual International Conference of the IEEE Engineering in Medicine and Biology Society; 1996 Oct 31-Nov 3; Amsterdam, Netherlands. Piscataway: IEEE; 1997. Vol. 2, p. 782-3. http://dx.doi.org/10.1109/IEMBS.1996.651974.

Blencowe H, Cousens S, Chou D, Oestergaard M, Say L, Moller A, Kinney M, Lawn J. Born too soon: the global epidemiology of 15 million preterm births. Reprod Health. 2013; 10(Suppl 1):S2-14. http://dx.doi.org/10.1186/1742-4755-10-S1-S2. PMid:24625129.

Bishop EH. Pelvic scoring for elective induction. Obstet Gynecol. 1964; 24(2):266-8. PMid:14199536.

Cunningham FG, Leveno KJ, Bloom SL, Hauth JC, Rouse DJ, Spong CY. Parturition. In: Cunningham F, Leveno K, Bloom S, Hauth J, Rouse D, Spong C. Williams obstetrics. 23rd ed. New York: McGraw-Hill; 2010. p. 136-72.

Danforth DN. The fibrous nature of the human cervix, and its relation to the isthmic segment in gravid and nongravid uteri. Am J Obstet Gynecol. 1947; 53(4):541-60. http://dx.doi. org/10.1016/0002-9378(47)90273-1. PMid:20291226.

Etemadi M, Chung P, Heller JA, Liu JA, Rand L, Roy S. Towards birth alert - a clinical device intended for early preterm birth detection. IEEE Trans Biomed Eng. 2013; 60(12):3484-93. http:// dx.doi.org/10.1109/TBME.2013.2272601. PMid:23893706.
Fricke H, Morse S. The electrical resistance of blood between 800 and 4.5 million cycles. J Gen Physiol. 1925; 9(2):153-67. http://dx.doi.org/10.1085/jgp.9.2.153. PMid:19872239.

Gandhi SV, Walker DC, Brown BH, Anumba DOC. Comparison of human uterine cervical electrical Impedance measurements derived using two probes of different sizes tetra. Biomed Eng Online. 2006b; 5(62):1-7.

Gandhi SV, Walker DC, Milnes P, Mukherjee S, Brown BH, Anumba DOC. Electrical impedance spectroscopy of the cervix in non-pregnant and pregnant women. Eur J Obstet Gynecol Reprod Biol. 2006a; 129(2):145-9. http://dx.doi.org/10.1016/j. ejogrb.2005.12.029. PMid:16517044.

Hendrix NW, Chauhan SP, Morrison JC, Magann EF, Martin JN Jr, Devoe LD. Bishop score: a poor diagnostic test to predict failed induction versus vaginal delivery. South Med J. 1998; 91(3):248-52. PMid:9521363.

Hoe YSG, Gurewitsch ED, Shaahinfar A, Hu ES, Sampattavanich $\mathrm{S}$, Ruffner $\mathrm{M}$, et al. Measuring bioimpedance in the human uterine cervix: Towards early detection of preterm labor. In: Proceedings of the 26th Annual International Conference of the IEEE Engineering in Medicine and Biology Society; 2004 Sep 1-4; San Francisco, USA. Piscataway: IEEE; 2004. Vol. 1, p. 2368-72. http://dx.doi.org/10.1109/IEMBS.2004.1403686.

Jokhi RP, Brown BH, Anumba DOC. The role of cervical electrical impedance spectroscopy in the prediction of the course and outcome of induced labour. BMC Pregnancy Childbirth. 2009; 9(40):1-8. https://doi.org/10.1186/1471-2393-9-40. PMid:19725953.

Kleissl HP, Van Der Rest M, Naftolin F, Glorieux FH, De Leon A. Collagen changes in the human uterine cervix at parturition. Am J Obstet Gynecol. 1978; 130(7):748-53. http://dx.doi. org/10.1016/0002-9378(78)90003-0. PMid:637097.

O’Connell MP, Tidy J, Wisher SJ, Avis NJ, Brown BH, Lindow SW. An in vivo comparative study of the pregnant and nonpregnant cervix using electrical impedance measurements. Br J Obstet Gynaecol. 2000; 107(8):1040-1. http://dx.doi. org/10.1111/j.1471-0528.2000.tb10410.x. PMid:10955439.

Pandis GK, Papageorghiou AT, Ramanathan VG, Thompson MO, Nicolaides KH. Preinduction sonographic measurement of cervical length in the prediction of successful induction of labor. Ultrasound Obstet Gynecol. 2001; 18(6):623-8. http:// dx.doi.org/10.1046/j.0960-7692.2001.00580.x. PMid:11844202.

Petersen LK, Oxlund H, Uldbjerg N, Forman A. In vitro analysis of muscular contractile ability and passive biomechanical properties of uterine cervical samples from nonpregnant women. Obstet Gynecol. 1991; 77(5):772-6. PMid:2014094.

Schwan HP. Electrical properties of tissue and cell suspensions. Adv Biol Med Phys. 1957; 5:147-209. http://dx.doi.org/10.1016/ B978-1-4832-3111-2.50008-0. PMid:13520431.

Uldbjerg N, Ekman G, Malmstrom A, Olsson K, Ulmsten U. Ripening of the human uterine cervix related to changes in collagen, glycosaminoglycans, and collagenolytic activity. Am J Obstet Gynecol. 1983; 147(6):662-6. http://dx.doi.org/10.1016/00029378(83)90446-5. PMid:6638110. 